\title{
Strain improvement for the production of antioxidant activity from Bacillus sp. by induced stress
}

\section{S. Priyadarshini*}

Department of Biotechnology for PG Studies and Research, Government Science College, Bangalore-560061, India

\section{R. Madhumadhurya}

Department of Biotechnology for PG Studies and Research, Government Science College, Bangalore-560061, India

\section{P. Shwetha}

Department of Biotechnology for PG Studies and Research, Government Science College, Bangalore-560061, India

\section{J. Kiran kumar}

Department of Biotechnology for PG Studies and Research, Government Science College, Bangalore-560061, India

\section{Mahesh}

Azyme Bioscience Pvt Ltd, $1188 / 2026^{\text {th }}$ main, $9^{\text {th }}$ block Jayanagar, Bangalore-560069, India

${ }^{*}$ Corresponding author. E-mail: priyadarshiniplm@gmail.com

\section{Article Info}

DOI:10.31018/jans.v10i2.1744

Received: December 22, 2017

Revised: March 23, 2018

Accepted: April 13, 2018

\section{How to Cite}

Priyadarshini, S. et al. (2018). Strain improvement for the production of antioxidant activity from Bacillus $s p$. by induced stress. Journal of Applied and Natural Science, 10(2): $614-619$

\begin{abstract}
In the present study, water samples were collected from different beaches in Chennai such as Marina beach, Elliott beach, VGP Golden beach and Kovalam beach to evaluate the best source for antioxidants. The bacteria were isolated on Starch Casein Agar media and screened for the antimicrobial activity. Among 11 isolates, 5 isolates showed antimicrobial potential which were further evaluated for the DPPH (2,2-diphenyl-1picrylhydrazyl) scavenging activity. Among 5 isolates, one sample showed significant DPPH scavenging activity with half minimal inhibitory concentration of (IC50)344.754 $\mathrm{gg} /$ $\mathrm{mL}$. The maximum antioxidant production was observed at $\mathrm{pH} 7$ and at temperature of $37^{\circ} \mathrm{C}$ with an IC50 of $188.66 \mu \mathrm{g} / \mathrm{mL}$ and $293.76 \mu \mathrm{g} / \mathrm{mL}$ respectively. The potent antioxidant producing strain was subjected for mutagenesis. In physical mutagenesis, the organism exposed for UV light for 25 minutes showed maximum antioxidant production with an IC50 of $133.55 \mu \mathrm{g} / \mathrm{mL}$. This mutant strain was then subjected for chemical mutagenesis with the addition of different concentrations of Ethidium bromide such as $10 \mu \mathrm{L}$, $20 \mu \mathrm{L}, 30 \mu \mathrm{L}, 40 \mu \mathrm{L}$ and $50 \mu \mathrm{L}$. The mutant strain obtained with the addition of $20 \mu \mathrm{L}$ Ethidium bromide (EtBr) showed significant antioxidant activity with an IC50 of $325.4 \mu \mathrm{g} / \mathrm{mL}$. The sample was purified by solvent extraction method and was evaluated for antioxidant production. The analyte was subjected to HPLC (High Performance Liquid Chromatography) analysis to avince the presence of antioxidants. The ethyl acetate extract showed the total phenolic content of $0.892 \mathrm{mg} \mathrm{GAE} / \mathrm{g}$ of dry extract. It also showed the total flavonoid content of $0.522 \mathrm{mg} \mathrm{RE} / \mathrm{g}$ of dry extract.
\end{abstract}

Keywords: Antioxidants, DPPH scavenging activity, HPLC, Mutagenesis

\section{INTRODUCTION}

The microbial extracts have served as a valuable source of diverse molecules in many drug discovery efforts and led to the isolation of several important drugs (Santas et al., 2008). They produce the most bioactive compounds that are potentially useful for human in pharmaceutical industry sector, for instance as antimicrobial, antifungal, antioxidant, anticancer and anti-inflammatory agents (Yoghiapiscessa et al., 2016).

Antioxidants are the free radical scavengers (Takao et al., 1994). Antioxidant compounds have an important role in improving human health and can decrease the risk of multiple chronic degenerative diseases, for instance gastrointestinal infection, cancer, Alzheimer's disease, cataract and coronary heart disease (Yoghiapiscessa et al., 2016).

Antioxidant properties have been reported from grains, cereals, medicinal herbs, plants, eggs, meat, legumes and nuts (Pereira et al., 2015). The study of microbial antioxidants came into focus in the early 1980s, although various studies have established a relationship between antioxidants 
and microorganisms (Gupta et al., 2013). However, studies on microorganisms with respect to antioxidant and free radical scavenging activities are very limited (Saravana Kumar et al., 2014)

Several works have been already reported on the antioxidant activity of bacteria. For instance, The probiotic bacteria Streptococcus thermophilus has been shown to aid malnutrition due to short-term fasting and reduce the associated intestinal disorders in animals. S. thermophilus is also known to have powerful antioxidant activity, protecting the body from aging, stress, sugar, antibiotics and other toxins (Gupta et al., 2013).

Further, the organisms like Bacillus simplex, BacilIus natto, Bacillus cereus, Lactobacillus dextranicum, Micrococcus freudenreichii, Sarcina lutea, Bacillus stearothermophilus, Bacillus longum, Lactobacillus acidophilus, Thermothrix species have also shown considerable antioxidant activity (Varinder et al., 2013).

In the present study, the research focus was to screen bacteria found in water bodies producing bioactive compounds and to determine potential bacterial isolates through the antimicrobial and antioxidant activities of the bacterial extracts.

\section{MATERIALS AND METHODS}

Collection of samples: The samples used in this study were collected from different beaches in Chennai such as Marina beach, Elliott beach, VGP Golden beach and Kovalam beach. The samples were collected using sterilised plastic bags and were then taken to the laboratory for further analysis.

Isolation and identification of organism: A known volume $(1 \mathrm{~mL})$ of each water sample was added to $9 \mathrm{~mL}$ of deionized water. Then the serial dilution method was carried out to obtain different concentrations ranging from $10^{-1}$ to $10^{-5}$, after which $500 \mu \mathrm{L}$ of the sample from the last dilution was aseptically drawn and poured onto the sterile petriplates. The Starch Casein Agar media (Starch-10g, Casein-1g, NaCl-37g, Agar-20g, Distilled water-1000mL) was poured on the inoculum and allowed to solidify. The petriplates were incubated for 24 hours at $37^{\circ} \mathrm{C}$. After the incubation, the colonies formed on the petriplates were subcultured on SCA slants. The isolated strain was identified to the genus level based on their morphological characters such as colour, shape, size, texture etc., of the bacterial colonies and biochemical characteristics such as IMViC tests, carbohydrate fermentation, nitrate reduction tests etc.

Preparation of cell free supernatant: Sterile Starch Casein broth (Starch-10g, Casein-1g, NaCl $-37 \mathrm{~g}$, Distilled water-1000mL) was inoculated with the obtained pure cultures of the isolates and incubated at $37^{\circ} \mathrm{C}$ for 24 hours. The cell free supernatant was obtained by centrifugation of this culture at $10000 \mathrm{rpm}$ for 10 minutes at $4^{\circ} \mathrm{C}$.

Estimation of antioxidant activity by DPPH assay: The free Radical scavenging activity using 1,1- diphenyl-2-picryl-hydrazyl (DPPH) reagent was determined according to the method given by Blois (Marsden., 1958). The cell free supernatant with different concentrations ranging from $10 \mu$ to $50 \mu \mathrm{l}$ were pipetted into different test tubes. $3 \mathrm{~mL}$ of freshly prepared DPPH solution was added and incubated in dark chamber for 15 minutes. Absorbance was recorded at $517 \mathrm{~nm}$ and compared with the control. The antioxidant activity was given as percentage of DPPH scavenging and the IC50 value was calculated (Akter et al., 2010)

Effect of $\mathrm{pH}$ on the production of antioxidant compound: To determine optimal $\mathrm{pH}$, the organism was cultivated in a conical flask containing $50 \mathrm{~mL}$ of Starch Casein broth with different $\mathrm{pH}$ ranging from 4-9. The $\mathrm{pH}$ of the medium was adjusted using $1 \mathrm{~N} \mathrm{HCl}$ and $0.2 \mathrm{M}$ phosphate buffer. The culture was incubated in a rotary shaker for 24 hours at $37^{\circ} \mathrm{C}$. After incubation, the cell free filtrate was used for DPPH assay.

Effect of temperature on the production of antioxidant compound: In order to determine the optimum temperature for the production of antioxidant compound, the Starch Casein broth was prepared in different conical flasks and was adjusted to $\mathrm{pH} 7.1 \mathrm{~mL}$ of the bacterial culture was inoculated and incubated at different temperatures such as $4^{\circ} \mathrm{C}, 37^{\circ} \mathrm{C}, 50^{\circ} \mathrm{C}$ and $60^{\circ} \mathrm{C}$ in a rotary shaker. After incubation, DPPH assay was performed as described earlier.

Effect of induced stress on the production of antioxidant compound

Effect of UV irradiation: Sterilized Starch Casein Agar media was poured into 5-6 petriplates and allowed to solidify. $100 \mu$ l of the culture was spread uniformly. The plates were exposed to UV light for different intervals of time such as 5, 10, 15, 20 and 25 minutes and incubated for 24 hours at $37^{\circ} \mathrm{C}$. After incubation, the colonies formed were sub-cultured on SCA slants. These cultures were inoculated in Starch Casein broth and incubated at $37^{\circ} \mathrm{C}$ for 24 hours. The cell free supernatant was prepared by centrifugation and the DPPH assay was performed.

Effect of chemical stress: $1 \mathrm{~mL}$ of sterilised Starch Casein Broth was taken in 5 different vials and inoculated with the bacterial culture and different concentration of Ethidium Bromide ranging from $10-50 \mathrm{~mL}$ was added to each vial. Incubate at $37^{\circ} \mathrm{C}$ for 24 hours. After incubation, the broth is centrifuged at $10,000 \mathrm{rpm}$ for 10 minutes and the DPPH assay was performed using the supernatant.

\section{Purification}

Production of pure culture: Sterile $250 \mathrm{~mL}$ Starch Casein broth with pH (7) was inoculated with the bacterial culture and incubated in shaker 
incubator for 24 hours. The cell free supernatant was prepared using this broth and the DPPH assay was performed.

Solvent extraction by ethyl acetate: In this method, equal volume of the supernatant and ethyl acetate were added in a separating funnel, mixed well and allowed to settle down for overnight. Formation of two immiscible layers observed i.e., organic layer and aqueous layer. The organic layer was taken and kept for drying in a water bath at $30-40^{\circ} \mathrm{C}$ for overnight. The dried powder $(10 \mathrm{mg})$ was dissolved in $1 \mathrm{~mL}$ of DMSO solution. Taking this solution, DPPH assay was performed.

High performance liquid chromatography (HPLC): Methanol and water was used in the ratio 7:3 to prepare mobile phase and was degassed. The crude sample and purified sample obtained was membrane filtered using nitrocellulose membrane. Further, $20 \mu \mathrm{L}$ of the sample was injected into the injector and the results were recorded.

\section{RESULTS AND DISCUSSION}

Isolation of the bacteria: Marine water bodies are the potential sources for isolation of novel bacteria yielding new products and are recognized as source of novel antibiotic and anticancer agents. Thus, bacteria represent an important group of microbes found in environment. In this study, 14 aerobic bacterial colonies were isolated on the basal media from 4 marine water bodies in Chennai. The macroscopic appearance of the

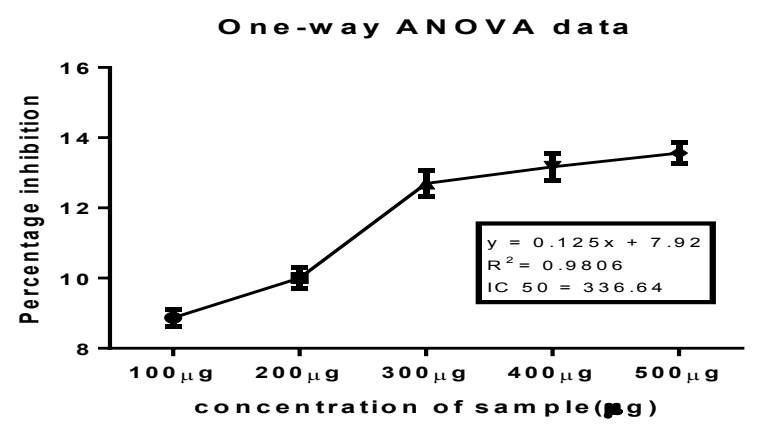

Fig. 1. Percentage inhibition shown by the bacteria at different concentrations.

Optimization of pH

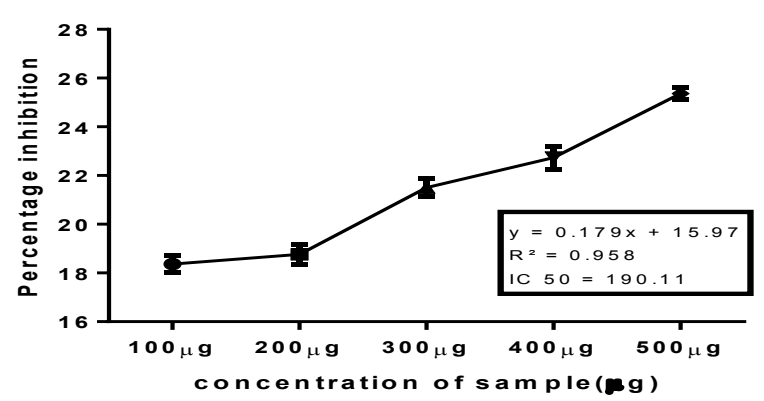

Fig. 2. Percentage inhibition shown by the bacteria at pH 7. isolates showed white smooth translucent colonies on the media.

DPPH radical scavenging activity: Besides antimicrobial activity, marine bacteria also develop unique metabolic and physiological capabilities, which enable them to survive in extreme habitats and to produce compounds that might not be produced by their terrestrial counterparts. Marine bacteria were isolated and screened for their antioxidant producing capacities. Since there is no specific method to evaluate the antioxidant activity of a compound/extract, due to different antioxidant mechanisms, the antioxidant activity was evaluated through 2,2-diphenyl-1-picrylhydrazyl (DPPH) radical scavenging activity. DPPH is a stable free radical, accepts protons from the antioxidant source and shows a decreasing absorption. In the present study, the bacteria that showed antimicrobial potential were evaluated for the DPPH scavenging assay and the DPPH activity was determined in percentage of inhibition.

It was witnessed that the bacteria in sample 2 showed significant level of DPPH radical scavenging activity than other samples. The bacteria in sample 2 showed an IC 50 of $336.64 / \mathrm{mL}$ that is comparable with the IC50 value of standard gallic acid $(10.8 \pm 0.02 \mathrm{ug} / \mathrm{mL})$. These results are extremely interesting, especially when compared with the work of Kalirajan and co-workers who evaluated the DPPH radical scavenging activity of bacteria associated with a marine sponge and obtained an $\mathrm{IC}_{50}$ of $857.49 \mu \mathrm{g} / \mathrm{mL}$, which is 2.5 times less

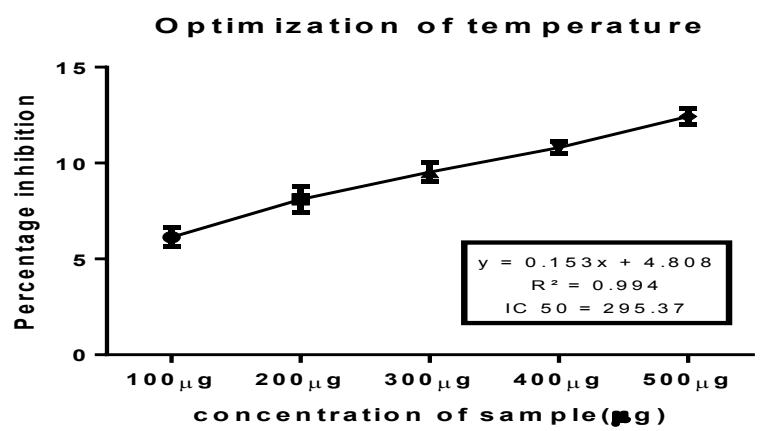

Fig. 3. Percentage inhibition shown by the bacteria at room temperature.

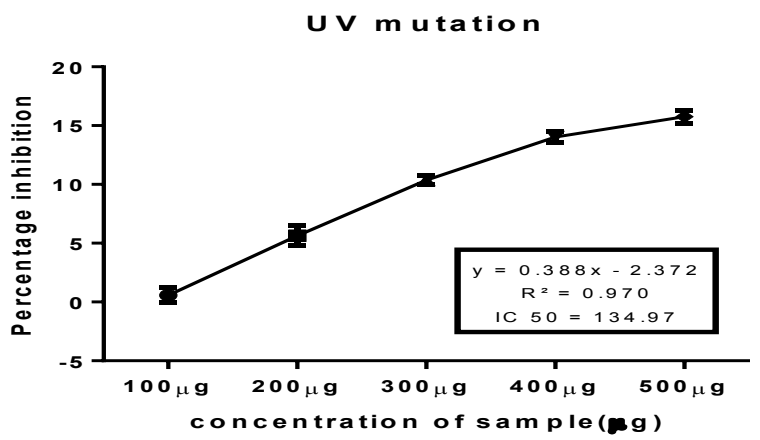

Fig. 4. Percentage inhibition shown by the bacteria after UV mutation. 


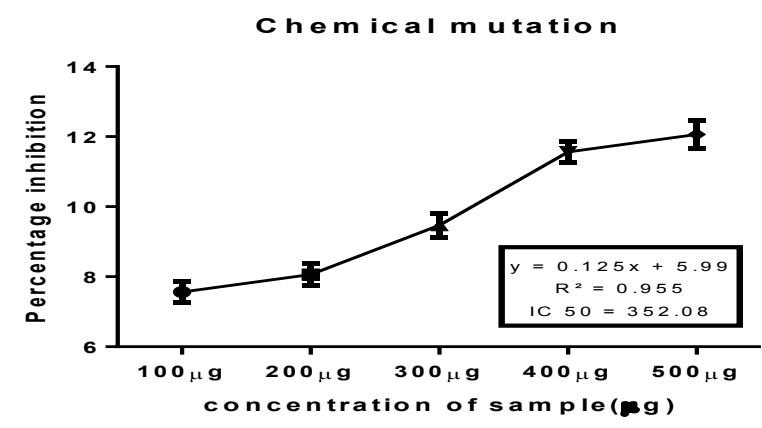

Fig. 5. Percentage inhibition shown by the bacteria after chemical mutation.

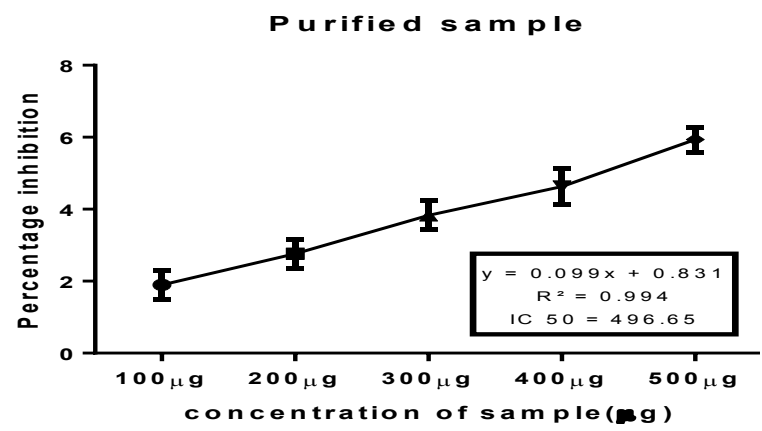

Fig. 6. Percentage inhibition shown by the bacteria after purification.

potent than that obtained for the bacteria in our work (Kalirajan et al., 2013).

Genus level Identification of potential isolate: The isolate recovered from the water sample appeared as a smooth, translucent white colony. It was identified as Gram positive rods from Gram staining. From the biochemical tests, the bacterium was identified as Bacillus species since it showed positive result for carbohydrate fermentation, catalase, starch hydrolysis and methyl red tests.

Effect of pH on the production of antioxidant compound: An important factor significantly affecting the production of antioxidant was the initial $\mathrm{pH}$. The production of antioxidant was carried out at different $\mathrm{pH}$ at $4,5,6,7,8$, and 9 . The table below shows the effect of medium $\mathrm{pH}$ on production

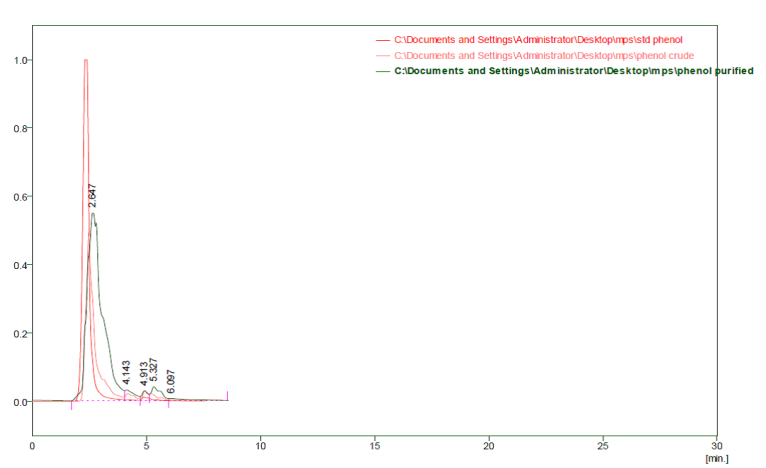

Fig. 7. HPLC chromatogram for the analysis of phenols extracted from bacteria by solvent extraction method.

\section{of antioxidant compound by the isolate.}

The Maximum antioxidant production is observed at $\mathrm{pH} 7$ which showed an IC50 value of $190.11 \mu \mathrm{g} /$ $\mathrm{mL}$. The results are in the accordance with the work in the case of antioxidant production by Pseudomonas flourescens at $\mathrm{pH} 7$ (Raza et al., 2014) and also with the results of Chowdhury in the case of Bacillus megaterium (Sougata et al., 2011).

Effect of temperature on the production of antioxidant compound: Temperature influences all the physiological activities in living cell and is one of the important environmental factors to control the growth, microbial activities, normal functioning of the cell. The production of antioxidant at different temperature viz., $4^{\circ} \mathrm{C}, 37^{\circ} \mathrm{C}, 50^{\circ} \mathrm{C}$ and $60^{\circ} \mathrm{C}$, was examined by keeping the other conditions constant. The table below shows the effect of temperature on the production of antioxidant.

The Maximum antioxidant production was observed at room temperature i.e., $37^{\circ} \mathrm{C}$ which showed an IC50 value of $295.37 \mu \mathrm{g} / \mathrm{mL}$. Mata et al (2008) have reported a maximum EPS production at $32^{\circ} \mathrm{C}$ in Alteromonadaceae sp., a halophilic bacterium which is likely in agreement with the present study. Also there are reports of maximum antioxidant production at temperatures ranging from 28 to $37^{\circ} \mathrm{C}$ (Raza et al., 2014; Sougata et al., 2011; Varinder et al., 2013).

Effect of induced stress on the production of antioxidant compound

Effect of UV irradiation: Ultraviolet (UV) light exerts its mutagenic effect by exciting electrons in molecules. The excitation of electrons in DNA molecules often results in the formation of extra bonds between adjacent pyrimidines in DNA (Suribabu et al., 2014). The UV light is the best studied mutagenic agent in prokaryotic organisms (Meenu et al., 2000). In the current study, the mutant strain which was subjected to UV treatment for 25 minutes showed maximum antioxidant production.

The mutant strain showed an IC50 of $134.97 \mu \mathrm{g} /$ $\mathrm{mL}$ which confirms that the mutant strain is more

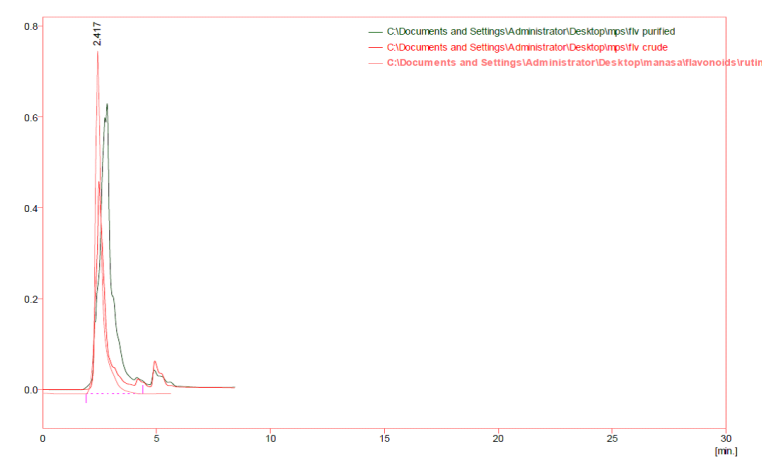

Fig. 8. HPLC chromatogram for the analysis of flavonoids extracted from bacteria by solvent extraction method. 
potent than the parental strain. Here, mutations were found to have enhanced the antioxidant production ability by 2.5 fold than the parental strain. Thus, in the present study, mutations were found to have contributed significantly in strain improvement with respect to the production of antioxidants.

Effect of Chemical stress: Chemical mutagens are stronger mutagenic agents which scause permanent changes in DNA sequence by bringing about transitions from G: C $\rightarrow$ A: T (Miller., 1972). Ethidium bromide (EtBr) acts as a mutagen because it intercalates double stranded DNA and deforms the DNA (Joyce et al., 1975). Different concentrations of Ethidium bromide was added to the UV mutant strain and was assayed for antioxidant production.

The maximum antioxidant production was observed with the addition of $20 \mu \mathrm{L}$ of Ethidium Bromide. The observed IC50 value was $352.08 \mu \mathrm{g} / \mathrm{mL}$ which showed slight increase in the antioxidant activity than the parent strain. Thus, in the present study, it can be concluded that the mutations play a very important role in the strain improvement of the bacteria in order to obtain a high yield of the metabolite.

\section{Purification}

Solvent extraction by ethyl acetate: The method used in the separation of antioxidants becomes essential for the accurate quantification and determination of antioxidant capacity (Santas et al., 2008). Several extraction conditions are reported in the literature, however there is no single extraction method which may be considered standard (Cacace and Mazza, 2003). The chemical nature of phenolic compounds, the extraction method employed, the sample particle size, storage time and conditions, as well as the presence of interfering substances affect the efficiency of the extraction methods (Joana et al., 2014). In the present study, ethyl acetate was used as an extraction solvent and the extracted solvent was used for the DPPH assay. The percentage of inhibition is shown graphically.

The purified extract showed an IC50 of $496.65 \mu \mathrm{g} /$ $\mathrm{mL}$. The solvent extraction using ethyl acetate led to the recovery of a potent antioxidant compound. Remya and Vijaykumar have reported the antimicrobial potential of compound obtained from ethyl acetate extract of Streptomyces strain RM42 (Mohan et al., 2008). Similarly, the extraction of antibiotics has been carried out from Streptomycetes by using various solvents including ethyl acetate and methanol.

High performance liquid chromatography (HPLC): High performance liquid chromatography constitutes a crucial, reliable technique for the characterization of phenolic compounds due to its versatility, precision and relatively low cost (Irene et al., 2002). Moreover, HPLC techniques offer a unique chance to analyze simultaneously all components of interest together with their possible derivatives or degradation products (Sakakibara et al., 2003). The introduction of reversed-phase (RP) columns has considerably enhanced HPLC separation of different classes of phenolic compounds and RP-C18 columns are almost exclusively employed (Sai et al., 2012). In this study, the analyte was subjected to HPLC analysis to avince for the presence of antioxidants. The results obtained were expressed in terms of $\mathrm{mg} / \mathrm{g}$ of dry extract. The ethyl acetate extract showed the total phenolic content of $0.892 \mathrm{mg} \mathrm{GAE} / \mathrm{g}$ of dry extract. It also showed the total flavonoid content of $0.522 \mathrm{mg} \mathrm{RE} / \mathrm{g}$ of dry extract. A number of works on Analysis of antioxidant compounds in plants using HPLC have been already reported. Very less works have been reported on the antioxidant compounds present in the bacteria (Shoib et al., 2015). Thus, HPLC analysis of the ethyl acetate extracts of this sample led to the identification of phenolic compounds and flavonoids in bacteria and our results confirmed the presence of compounds to be responsible for showing antimicrobial and antioxidant activities. The results obtained here is in accordance with the results of the work reported on extraction and identification of antibacterial secondary metabolites from marine Streptomyces sp. VITBRK2 (Benita et al., 2014). This study thus confirms the potential of the bacteria as a valuable source of bioactive compounds and could be potential alternatives for synthetic antimicrobial drugs and antioxidants.

\section{Conclusion}

The marine bacterial isolates from different water sources of Chennai, India exhibited antioxidant activity with an IC50 of $344.75 \mu \mathrm{g} / \mathrm{mL}$ which revealed a potential source of novel antioxidant compounds. The organism was found to be Bacillus $\mathrm{sp}$. by performing gram staining and various biochemical tests. Strain improvement of the bacteria was carried out by using physical and chemical mutagens such as UV light and Ethidium Bromide. The bacteria showed IC50 of $133.55 \mu \mathrm{g} / \mathrm{mL}$ with UV light which was 2.5 fold higher than the wild parent strain. Also, the antioxidant activity increased slightly with the chemical mutagen with an IC50 of $325.4 \mu \mathrm{g} / \mathrm{mL}$. Further, a simple and reliable extraction technique, and a validated HPLC method were developed for the simultaneous separation and quantification of antioxidants from the bacteria.

\section{REFERENCES}

Akter, S., Ahmed, M., Eun, J.B. (2010). Solvent effects on antioxidant properties of persimmon (Diospyros kaki L. cv. Daebong) seeds. Int J. Food Sci. Tech. 45, 2258-2264

Benita Mercy Rajan, Krishnan Kannabiran. (2014). Ex- 
traction and Identification of Antibacterial Secondary Metabolites from Marine Streptomyces sp. VITBRK2. Int J Mol Cell Med Summer; 3(3): 130-137

Cacace, J.E. Mazza, G. (2003). Mass transfer process during extraction of phenolic compounds from milled berries. Journal of Food Engineering; 59(4): 379-89

Gupta, Charu, Dhan Prakash, Sneh Gupta. (2013). Functional Foods Enhanced with Microbial Antioxidants. Academic Journal of Nutrition, 2(2): 10-18

Yoghiapiscessa, Daning, Irmanida., Batubara,Aris., Tri Wahyudi.(2016). Antimicrobial and Antioxidant Activities of Bacterial Extracts from Marine Bacteria Associated with Sponge Stylotella sp.. American Journal of Biochemistry and Biotechnology; 12 (1): 36-46

Irene Parejo, Francesc Viladomat, Jaume Bastida, Alfredo Rosas-Romero, Nadine Flerlage, Jesús Burillo and Carles Codina. (2002). Comparison between the Radical Scavenging Activity and Antioxidant Activity of Six Distilled and Nondistilled Mediterranean Herbs and Aromatic Plants. Journal of Agricultural and Food Chemistry; 50 (23): 6882-6890

Joana Schuelter Boeing, Érica Oliveira Barizão, Beatriz Costa e Silva, Paula Fernandes Montanher, Vitor de Cinque Almeida, Jesuí Vergilio Visentainer. (2014). Evaluation of solvent effect on the extraction of phenolic compounds and antioxidant capacities from the berries: application of principal component analysis. Chemistry Central Journal; 8:48

Joyce Mccann, Edmund Choi, Edith Yamasaki and Bruce N. Ames. (1975). Detection of carcinogens as mutagens in the Salmonella/microsome test: Assay of 300 chemicals. Proc. Nat. Acad. Sci.; 72(12):51355139

Kalirajan Arunachalam, Ranjitsingh Amirtham, Jacob Appadorai. (2013). Antioxidant potential and biochemical evaluation of metabolites from the marine bacteria sp. associated with the sponge. Free Radicals and Antioxidants; 3(1): 47-51

Mata, J.A. Bressollier, P. Tallon, R. Urdaci, M.C. Quesada, E. and Llamas, I. (2008). Characterization of exopolysaccharides produced by three moderately halophilic bacteria belonging to the family Alteromonadaceae. Journal of Applied Microbiology;105: 521528

Marsden S. Blois. (1958). Antioxidant Determinations by the Use of a Stable Free Radical. Nature; 181: 11991200

Meenu Madan. Dhillon, S. Singh, R. (2000). Production of alkaline protease by a UV-mutant of Bacillus polymyxa. Indian Journal of Microbiology; 40: 25-28

Miller, J.H. (1972). In: Experiments in molecular genetics. 11th edition Cold Spring Harbor Laboratory, Cold Spring Harbor, New York; 113

Mohan Remya, Ramasamy Vijayakumar. (2008). Isolation And Characterization Of Marine Antagonistic Actinomycetes From West Coast Of India. Medicine and Biology; 15(1): 13 - 19
Raza, W. Jun, Y. Faheem, M. Shah, M.A.A. and Shen, Q. (2014). Partial structural linkages and physicochemical activities of an extracellular polysaccharide produced by Pseudomonas fluorescens strain WR-1. Int. J. Agric. Biol.; 16: 971-975

Sai Lakshman Mithun,V. Ramachandra Rao, C.S.V. (2012). Isolation and Molecular Characterization of Anti-Cancerous Compound Producing Marine Bacteria by Using $16 S$ rRNA Sequencing and GC-MS Techniques. International Journal of Modern Engineering Research; 2(6): 4510-4515

Sakakibara, H. Honda, Y. Nakagawa, S. Ashida, H. Kanazawa, K. (2003). Simultaneous determination of all polyphenols in vegetables, fruits, and teas. J Agric Food Chem.; 51(3):571-581

Santas, J. Carbo,R. Gordan, M.H. and Almajano, M.P. (2008). Comparison of the antioxidant activity of two Spanish onion varieties. Food Chemistry; 107(3): 1210-1216

Saravana Kumar, P. Al-Dhabi, N.A., Duraipandiyan, V. Balachandran, C. Praveen Kumar, P. and Ignacimuthu, S. (2014). In vitro antimicrobial, antioxidant and cytotoxic properties of Streptomyces lavendulae strain SCA5. BMC Microbiology; 14:291

Pereira Sheryanne Velho, Parvatkar, P. and Irene J. Furtado. (2015). Evaluation of Antioxidant Producing Potential of Halophilic Bacterial Bionts from Marine Invertebrates. Indian J Pharm Sci;77(2):183-189

Shoib A. Baba, Shahid A. Malik. (2015). Determination of total phenolic and flavonoid content, antimicrobial and antioxidant activity of a root extract of Arisaema jacquemontii Blume. Journal of Taibah University for Science; 9: 449-454

Sougata Roy Chowdhury, Ratan Kumar Basak, Ramkrishna Sen and Basudam Adhikari. (2011). Optimization, dynamics, and enhanced production of a free radical scavenging extracellular polysaccharide (EPS) from hydrodynamic sediment attached Bacillus megaterium RB-05. Carbohydrate Polymers; 86 (3):1327-1335

Suribabu, K. Lalitha Govardhan, T. and Hemalatha, K.P.J. (2014). Strain Improvement of Brevibacillus borostelensis R1 for Optimization of a -Amylase Production by Mutagens. Microb Biochem Technol; 6(3): 123-127

Takao Tomohiro, Futoshi Kitatani, Naoharu Watanabe, Akihito Yagi \& Kanzo Sakata. (1994). A Simple Screening Method for Antioxidants and Isolation of Several Antioxidants Produced by Marine Bacteria from Fish and Shellfish. Bioscience, Biotechnology, and Biochemistry; 58(10):1780-1783

Varinder Kaur, Bera, M.B. Panesar, P.S. Chopra, H.K. (2013). Production and Characterization of Exopolysaccharide Produced by Alcaligenes Faecalis B14 Isolated from Indigenous Soil. International Journal of Biotechnology and Bioengineering Research.; 4(4): 365-374 